\title{
On Moral Obligations and Our Chances of Fulfilling Them
}

\section{Farbod Akhlaghi ${ }^{1}$}

Accepted: 29 June 2020 /Published online: 14 July 2020

(C) The Author(s) 2020

\begin{abstract}
Many actions we perform affect the chances of fulfilling our moral obligations. The moral status of such actions is important and deeply neglected. In this paper, I begin rectifying this neglect by asking: under what conditions, if any, is it morally wrong to perform an action that will lower the chance of one fulfilling a moral obligation? In $\S 1$, I introduce this question and motivate concern with its answer. I argue, in $\S 2$, that certain actions an agent has good reason to believe will drastically lower their chances of fulfilling a moral obligation in the future, relative to at least one alternative action available, are pro tanto morally wrong. This answer, I argue, captures our intuitions in a range of cases, avoids the problems that other views considered here face, and can be plausibly defended against some independent objections. I conclude in $\S 3$ by noting some consequences for normative and practical ethics of the moral wrongness of at least some actions that lower the chances of fulfilling our moral obligations, and by raising a series of important questions regarding these actions for future consideration.
\end{abstract}

Keywords Chance-affecting actions · Moral obligation $\cdot$ Moral wrongness $\cdot$ Normative ethics $\cdot$ Practical ethics

Farbod Akhlaghi

farbod.akhlaghi-ghaffarokh@philosophy.ox.ac.uk

Faculty of Philosophy, University of Oxford, Oxford OX2 6GG, UK 


\section{Introduction}

We have moral obligations. What moral obligations we have is contentious. Some relatively uncontroversial ones are moral obligations we have towards our friends, family, and to any moral agent in virtue of their being a moral agent. For example, one may have a moral obligation to help a friend, to support a parent in old age, or to minimally respect another's autonomy as a moral agent. ${ }^{1}$

We can succeed in meeting, or fail to fulfil, our moral obligations. Ceteris paribus, fulfilling a moral obligation is morally right and failing to fulfil one is morally wrong. Other things being equal, if I am morally obligated to aid my ailing relative, then if I do I have done something morally right; if I do not, I have done something morally wrong. What moral obligations we have, why we have them, and the moral status of fulfilling them are much discussed.

But there is a class of actions we perform and activities we engage in which, whilst falling short of involving success or failure in fulfilling our moral obligations, affect the chances of fulfilling our moral obligations. ${ }^{2}$ Call any action that one can perform which increases or decreases the objective probability of performing some further action that they are morally obligated to perform at a later time a chance-affecting action.

What is the moral status of chance-affecting actions? This question is largely neglected in normative ethics. To my knowledge, there is little to no work that directly addresses it. ${ }^{3}$ In this paper, I begin to rectify this neglect by asking:

(The Question): Under what conditions, if any, is it morally wrong to do something that

will lower the objective probability of one fulfilling their moral obligation(s)?

Failing to address the moral status of chance-affecting actions simpliciter, or answer (The Question) in particular, is deeply problematic for at least three reasons.

First, even if it is, e.g., morally wrong to fail to fulfil a moral obligation, this alone does not tell us whether there are some conditions which, if met, make the performing of actions that affect our chances of fulfilling such moral obligations morally right or wrong. Answering (The Question), and others regarding the moral status of chance-affecting actions, appears to require more than determining the moral status of meeting a moral obligation.

\footnotetext{
${ }^{1} \mathrm{I}$ assume that an agent, $\mathrm{X}$, has a moral obligation to $\Phi$ just in case $\mathrm{X}$ is morally required to $\Phi$, where what $\mathrm{X}$ is morally required to do is just what $\mathrm{X}$ has best normative moral reason to do. These assumptions are harmless here since nothing I argue depends upon them.

2 I use 'chance(s)' and 'objective probability' interchangeably. By 'objective probability', I mean the likelihood of some $x$ occurring independently of any actual or hypothetical agent, evaluator, or utterer's doxastic state(s). Beyond understanding objective probability as distinct from subjective and evidential probabilities, I remain silent on the correct account of objective probability.

${ }^{3}$ Some important work addresses very closely related questions. Cordelli (2018) argues that it is pro tanto morally wrong for an agent to do something that will foreseeably make it impossible for them to carry out an obligation they are already bound by. Such principles, much discussed before Cordelli's excellent paper, are silent on the moral status of actions we perform that, whilst not making it impossible to fulfil a moral obligation, lower (or increase) our chances of doing so. Goodin (2012: 20) addresses duties to make possible or impossible the fulfilment of a duty, which are similarly silent on chance-affecting actions. Herzog (2018: 53-66) relatedly examines obligations to organise organisations and societies to promote better future behaviour. The general question of whether actions promoting particular outcomes or states of affairs provides a reason to perform them is similarly related: see Elson 2019 on this general question, and Nussbaum's 2004 orthodox reading of Kant on indirect duties to non-human animals that touches upon my concerns. My thanks to an anonymous reviewer for the second and third reference.
} 
Second, chance-affecting actions are ubiquitous. For example, notice that systematic engagement in types of actions such as smoking, drug abuse, and neglecting one's own physical and mental well-being will (or at least are highly likely to) lower our chances of fulfilling our moral obligations in the future (by, e.g., making one unwell or likely to neglect the concerns of others).

The moral status of these types of actions, and other chance-affecting actions, remains unclear. One way that we might examine their moral status, however, is by examining the moral status of a general feature that they all share: they are chance-affecting actions. And, here, the above are all actions that (are at least likely to) lower the chances of fulfilling a moral obligation in the future. Of course, a moment's reflection will reveal that the ubiquity of chance-affecting actions extends far beyond these examples since, for any given moral obligation, we might engage in myriad actions that will affect its chance of being fulfilled.

Finally, if there are some conditions that render, for example, the performing of actions that lower the chances of fulfilling our moral obligations morally wrong, then this generates a hitherto unnoticed adequacy condition for general normative ethical theories: any theory that purports to account for the moral status of all morally-evaluable actions must be able to explain the moral status of these actions.

Without addressing the moral status of chance-affecting actions in general, or at least answering (The Question), it will remain unclear whether such a constraint obtains and whether any normative ethical theory should be trying to meet it. Should such a constraint obtain, this provides novel grounds on which to argue for or against normative ethical theories by appeal to whether they explain the moral status of chance-affecting actions.

The stakes, then, are high. I proceed as follows. In §2, I consider a number of answers to (The Question). I argue that we have good reason to reject all but the final answer considered, which I maintain captures our intuitions in a range of cases, avoids the objections other answers face, and can be defended against some independent objections. I conclude in $\S 3$.

In what follows, I make two simplifying assumptions. First, I bracket whether the moral obligations considered in the chance-affecting cases below are actually fulfilled. For I am interested in the moral status of chance-affecting actions regardless of whether the relevant moral obligations are fulfilled, and so shall assume the former does not depend upon the latter. Second, I am concerned only with the moral status of voluntary actions by an agent that will lower the chances of fulfilling a moral obligation. Nothing argued for here depends on these assumptions, and they only serve to clarify the particular chance-affecting actions with which I am concerned. Let's proceed.

\section{The Moral Status of Chance-Affecting Actions}

Some may think it obvious that performing any action that lowers the objective probability of fulfilling a moral obligation is morally wrong. For by performing an action that lowers the chances of fulfilling a moral obligation, you make it less likely that you will perform an action you are morally required to perform. So, the following may seem obvious:

(A) If an agent, $\mathrm{X}$, is under a moral obligation at a time $t$ to perform some action at a later time $t^{\prime}$, and faces a choice between (at least) two actions, $\Phi$ and $\Psi$, then if performing $\Phi$ 
as opposed to $\Psi$ will lower X's chance of fulfilling their moral obligation at $t^{\prime}$, then it is morally wrong for X to $\Phi .^{4}$

To explain: suppose that today $(t)$ you have a moral obligation to deposit a cheque tomorrow $\left(t^{\prime}\right)$ for your friend to pay for his flight to see an ailing relative. Suppose, further, that you face a choice today between two actions, $\Phi$ and $\Psi$, where performing them makes the probability that you will deposit the cheque promptly 0.99 and 1.0 respectively. ${ }^{5}$

According to (A), it would be morally wrong to perform $\Phi$. For it would lower the chances of performing this action for your friend relative to at least one other action available to you, $\Psi$. But this seems false.

That is, the fact that a given action lowers the objective probability of performing some other morally obligatory act by some very small extent, relative to another action available to you, does not seem morally wrong. To illustrate this further, consider:

Car: Your best friend, Adam, calls you in need of urgent help. You are the only person who can help him and can do so at little cost to yourself. You have two ways to get to Adam: taking your car or the final bus on the requisite route which is presently outside your house. Taking your car will require driving amongst other cars, whilst the bus will drive through empty bus lanes. You opt for your car.

It seems, first, that you have a moral obligation to help Adam in the immediate future. Second, that getting in your car to drive to Adam will, to some extent, lower the objective probability of helping him relative to taking the final bus - since you incur the risk of accident, however small, whilst you do not if you take the final bus as it will be the only vehicle on the dedicated bus lane.

It does not seem, however, that by taking your car you would be doing anything morally wrong. Adam, for example, would have no strong moral complaint against you for doing so, and you would be taking a mode of transport that does not render your chances of fulfilling your obligation to him extremely slim (even if doing so lowers your chances of helping him relative to taking the bus).

If so, these cases show that it is false that any action that lowers the objective probability of fulfilling a moral obligation to some very small extent, relative to another action available to that agent, is morally wrong. So, (A) is false.

\footnotetext{
${ }^{4}$ More formally, (A) is equivalent to:

(A') If any agent, $\mathrm{X}$, is under a moral obligation at $t$ to perform some action $\Phi$ at some later time $t^{\prime}$, and $\mathrm{X}$ can perform one of a set of actions $\Psi_{1} \ldots \Psi_{\mathrm{n}} \in \mathrm{A}$, then if $\mathrm{X}$ performs an action $\Psi_{1} \in \mathrm{A}$ which lowers the objective probability of $\Phi$-ing at $t^{\prime}$ relative to at least one other action in A, then X's performing $\Psi_{1}$ is morally wrong.

The actions in $\Psi_{1} \ldots \Psi_{\mathrm{n}} \in \mathrm{A}$ are taken as mutually exclusive and exhaustive, such that A comprises all of the actions available to an agent at a time, and that the agent can perform at most one of $\Psi_{1} \ldots \Psi_{\mathrm{n}} \in \mathrm{A}$. (A), then, entails that when an agent chooses between two mutually exclusive actions, performing the action that lowers the chances of fulfilling a moral obligation at a future time, relative to the other, is morally wrong. Finally, by 'lowering' the chance of fulfilling an obligation by $\Phi$-ing as opposed to $\Psi$-ing, I intend a comparison of the relative chance of performing the obligated action conditional upon $\Phi$-ing compared with the conditional chance of performing the obligated action when $\Psi$-ing, where the conditional probability of doing the obligated act is lower in one case than the other.

${ }^{5}$ Construing objective probability as wholly belief and evidence independent, one might worry that I must assume ontic indeterminism for there to be objective chances other than 0 or 1 . I remain agnostic here, granting that if objective chances of this kind requires ontic indeterminism, and if ontic indeterminism is false, then there are no moral requirements concerning objective-chance-affecting actions. Since the first two claims are deeply controversial (see, e.g., Lewis 1980, Hoefer 2005, Nina 2017), the force of this worry is unclear at best and I henceforth bracket it.
} 
But now consider:

Car*: Same as Car, except your car is extremely unreliable. The overwhelming majority of times you have driven your car, it has broken down during your journey in need of repair. Despite this, you opt for your car.

Unlike Car, it does seem morally wrong for you to take your car in Car*. Relative to taking the bus, taking your car here will drastically decrease your chances of fulfilling your moral obligation to Adam (since it is very likely to break down). This is not the case in Car, where taking your car would only slightly lower your chances of fulfilling your moral obligation to Adam relative to taking the bus.

To answer (The Question) we need an explanation of the intuitive difference in the moral status of the actions you perform in Car and Car*. I suggest the salient difference is this: the extent to which the action you perform lowers your chances of fulfilling your moral obligation, relative to at least one other action available to you, drastically differs. In the former, the extent to which your chances of fulfilling your moral obligation are lowered appears insignificant. This is not so in Car*.

Since all else is equal between these cases, yet it seems that performing the chance-affecting action in $\mathrm{Car}^{*}$ is morally wrong and not so in $\mathrm{Car}$, this is good reason to think that the fact that taking your car in Car* is an action that will drastically decrease the objective probability of fulfilling your moral obligation (as opposed to one that, relative to other actions, only slightly lowers it) explains the intuitive wrongness of taking your car in that case and not the other.

This suggests:

(B) If an agent, $\mathrm{X}$, is under a moral obligation at a time $t$ to perform some action at a later time $t^{\prime}$, and faces a choice between (at least) two actions, $\Phi$ and $\Psi$, then if performing $\Phi$ as opposed to $\Psi$ will drastically lower X's chance of fulfilling their moral obligation at $t$, then it is morally wrong for $\mathrm{X}$ to $\Phi$.

(B) captures our intuitions. It entails that, in $\mathrm{Car}^{*}$, you are doing something morally wrong by taking your car which - relative to taking the bus - will drastically lower the chances of fulfilling your moral obligation. Additionally, it does not entail that in Car or the case used to illustrate (A) that you are doing anything morally wrong. These chance-affecting actions are not ones that will drastically decrease the chances of fulfilling your moral obligation relative to other actions available to you. ${ }^{6}$

(B), however, is false. For consider:

Charity: You donate $£ 10$ a month to a charity that aims to alleviate extreme poverty in a distant country. Unbeknownst to you, every month this money has been intercepted by a

\footnotetext{
${ }^{6}$ A difference between Car and Car* is that the extent to which your chances of fulfilling your moral obligation are affected seem negligible in the former but not the latter. Perhaps, then, a principle that renders morally wrong actions that pass some 'non-negligible' threshold of chance-lowering would best explain the intuitive difference between these cases, and not one that cites how much of a relative decrease constitutes a wrong act. There is very good reason to deny this. First, whilst capturing the intuitive difference, it does not explain the difference by appeal to any feature of the cases (instead relabelling the apparent non-negligible difference our intuitions are tracking). Second, to cite a non-negligible threshold that has to be violated presupposes some account of why this difference is morally non-negligible, and such an account is best provided by more specific principles like (B) and the ones soon to be considered. Third, admitting of some threshold in a principle to explain our intuitions in Car and Car* forces us to admit indeterminacy regarding precisely where such a threshold lies. (B), and other principles that concern actions that will drastically lower our chances of fulfilling some moral obligation, are silent on where (if anywhere) such a threshold lies, and only concern a clear set of actions that we do intuitively find morally wrong.
} 
ruthless gang leader in that country who uses it to fund his pillaging of nearby towns.

When next month comes and donations for this charity are being accepted, you decide to donate to the same charity again.

It is plausible that you have a moral obligation to contribute to some extent to alleviating extreme poverty. This obligation, in Charity, may obligate you to donate money at a time at which donations are being accepted and where you can contribute at little cost to yourself.

By donating your money in the coming month to the same charity, you would be performing an action that will drastically decrease the objective probability of fulfilling your moral obligation to contribute to the alleviation of extreme poverty, relative to, say, donating to another similar charity (since it is highly likely to be intercepted).

According to (B), your action would be morally wrong. But it does not seem to be morally wrong, despite it, relative to some other action available to you (like donating to a different charity), drastically decreasing the chances of fulfilling your moral obligation to help end extreme poverty. (B), then, is false.

For all you know in Charity, your act of donation is one that is likely to lead to meeting your moral obligation to aid in the alleviation of extreme poverty. Charity illustrates that one can perform an action they do not think will lower the chances of fulfilling some moral obligation but in fact does. Such actions, as Charity reveals, do not seem to be morally wrong.

The problem with (B) is that it ignores the epistemic limitations that agents may face regarding the likely effect of an action on the chances of that agent fulfilling their moral obligation in question. But, as we've seen, there are some actions which lower such chances that do seem morally wrong. This suggests a third answer to (The Question):

(C) If an agent, $\mathrm{X}$, is under a moral obligation at a time $t$ to perform some action at a later time $t^{\prime}$, and faces a choice between (at least) two actions, $\Phi$ and $\Psi$, then if performing $\Phi$ as opposed to $\Psi$ is an action $\mathrm{X}$ has good reason to believe will drastically lower X's chance of fulfilling their moral obligation at $t$ ', then it is morally wrong for $\mathrm{X}$ to $\Phi .^{7}$

This view has a number of attractive features.

First, it captures our intuitions in the case illustrating (A) and in Car, since it does not entail that you would be doing anything morally wrong by choosing an action that lowers your chances of fulfilling your moral obligation - relative to another action available - by a small extent.

Second, it entails that you would be doing something wrong by taking your car in Car*, since doing so is an action that you have good reason to believe - on the basis of the car's past performance - to be an action that will drastically decrease your chances of fulfilling your obligation to Adam.

\footnotetext{
${ }^{7}$ Note that the 'good reason to believe' qualifier concerns the possession of normative epistemic reasons to believe that an action is likely to have certain effects on the objective probability of fulfilling some moral obligation. An anonymous reviewer helpfully highlighted another noteworthy option that space-constraints prohibit discussion of here: qualifying $(\mathrm{C})$ to be about those effects on the chance of obligation-fulfilment that the agent could reasonably be expected to have discovered. But I note that, if needed, the view I ultimately defend could be unproblematically revised in that way.
} 
Finally, it does not entail that you are doing anything wrong in Charity: the 'good reason to believe' clause ensures that performing actions that you lack evidence regarding the chanceaffecting features of does not render your action morally wrong. Rather, it concerns only those actions that agents have good reason to believe will have certain effects on the chances of fulfilling a moral obligation at a future time.

Despite this, there is good reason to believe that (C) is false. For consider:

War: You are called to fight in a just war in which the army of another country is invading your own nation. You are one of a small number of people eligible to fight in the war. To fight, you must leave your family, comprised of your spouse and your child. You accept the call and go to war.

In War, it is plausible that you are under a moral obligation to fight in the war (since it is a just war, and you are one of a small number of people eligible to fight in it). You, also, are under a range of moral obligations to (amongst others) your family to do various things for them in the future.

If you accept the call, however, you will be performing an action that, relative to declining the call, is one that you have good reason to believe will drastically decrease the chance of fulfilling at least some familial moral obligations in the future (since you are likely to either merely be physically absent from your family, to become debilitatingly wounded, or die).

(C), then, entails you have done something morally wrong by going to war. But War looks like a counterexample to (C). Despite doing something that you have good reason to believe will drastically decrease your chances of fulfilling at least one moral obligation, War seems to show that such an action is not morally wrong. So, (C) is false.

Consider, further, a variant of Car. Suppose that, whilst in your car, you notice an injured person on the side of the road. Further suppose that this person will die without medical attention, you are the only person who can help them to receive such attention, and by taking this detour to the hospital you drive in the opposite direction to Adam.

You face a choice of either taking the detour to save this person's life or driving on to Adam. Again, despite being under a moral obligation to help Adam, and having good reason to believe taking this detour (as opposed to driving on) will lower your chances of meeting your obligation to him, it does not seem morally wrong to take the detour to save this other person's life.

Now note, first, that there are clear cases where performing an action you have good reason to believe will lower your chance of fulfilling a moral obligation seems morally wrong - such as $\mathrm{Car}^{*}$ and analogous cases. Second, in both of the above counterexamples to $(\mathrm{C})$, there seems to be a competing moral consideration that outweighs any moral wrongness of performing an action you have good reason to believe will lower the chances of fulfilling your moral obligation.

I submit that what cases like War and the last variant on Car above show is that actions we have good reason to believe will drastically lower our chances of fulfilling a moral obligation are pro tanto moral wrongs. That is, they are moral wrongs that can be outweighed by competing moral considerations.

This allows us to capture that some chance-affecting actions in cases we have considered are morally wrong, and that this moral wrongness seems to be outweighed in at least those cases where performing the relevant chance-affecting action allows us to bring about another 
action we have stronger moral reasons to perform (such as defensive fighting against unjust threateners or saving a morally innocent life). ${ }^{8}$

One may object that what War and our Car variant show is that the chance-affecting action is not morally wrong at all. That is, that if performing an action that you have good reason to believe will drastically lower your chance of fulfilling a moral obligation allows you to bring about some weightier moral good, then performing that action is not even pro tanto morally wrong.

This is false. Suppose that in the variant of Car above you called Adam on the way to the hospital to apologise for taking the detour. Notice that your apologising does not seem inappropriate, since you are doing something that makes it very unlikely that you will succeed in fulfilling your moral obligation to him. But if you were not doing anything wrong by taking the detour, then it would be inappropriate to apologise. So, this objection fails.

We arrive, then, at:

(D) If an agent, $\mathrm{X}$, is under a moral obligation at a time $t$ to perform some action at a later time $t^{\prime}$, and faces a choice between (at least) two actions, $\Phi$ and $\Psi$, then if performing $\Phi$ as opposed to $\Psi$ is an action X has good reason to believe will drastically lower X's chance of fulfilling their moral obligation at $t^{\prime}$, then it is pro tanto morally wrong for X to $\Phi$.

Of the answers considered, (D) is the most plausible answer to (The Question).

First, it does not entail that all actions that lower the chance of fulfilling a moral obligation by even some small extent relative to at least one other action available are morally wrong (the cheque case and Car).

Second, it captures our intuition that when agents perform actions that they have good reason to believe are very likely to drastically lower their chances of obligation-fulfilment, they are doing something morally wrong $\left(\mathrm{Car}^{*}\right)$.

Third, it acknowledges that, in cases where agents do not have good reasons to believe their actions are ones that will drastically lower their chances of fulfilling their moral obligations, the agent does not act wrongly by performing such actions (Charity).

Fourth, it achieves the aforementioned whilst allowing that there are cases (like War and our last Car variant) where the moral wrongness of performing a chance-affecting action can be outweighed by competing moral considerations (whilst still being a moral wrong).

(D) concerns the performing of a single chance-affecting action. But, as mentioned in $\S 1$, some actions that we perform are tokens of types of action that we have good reason to believe the systematic performance of which will drastically decrease our chances of fulfilling a moral obligation at some later time.

The analogue principle to (D) in the case of engagement in such activities is also plausible:

(D*) If an agent, $\mathrm{X}$, is under a moral obligation at a time $t$ to perform some action at a later time $t^{\prime}$, and faces a choice between (at least) two types of action, $\Phi$ and $\Psi$, then if systematically engaging in tokens of $\Phi$ as opposed to $\Psi$ is something $\mathrm{X}$ has good reason to believe the systematic performance of which will drastically lower X's chance of fulfilling a moral obligation at $t^{\prime}$, then it is pro tanto morally wrong for $\mathrm{X}$ to systematically $\Phi$.

To see why, take:

\footnotetext{
${ }^{8}$ Another possible reason to think that the moral wrongness of performing chance-affecting actions that meet (D) is pro tanto is that the wrongness of performing an action which you have good reason to believe will drastically decrease the chance of fulfilling an obligation might be outweighed by the fact that the agent did ultimately meet the obligation. As I've bracketed these questions, I only note this here.
} 
Pill: You have a moral obligation at time $t_{0}$ to help someone at time $t_{10}$. At $t_{0}$, you are given the choice to take a course of pills from $t_{0}$ to $t_{10}$. Each pill provides some pleasure for a brief period after consumption whilst doing some minor, imperceptible harm to you. You are reliably informed that whilst consumption of a single pill will not significantly harm someone, those who take these pills systematically over a period of time will become extremely physically unwell. You take the pills.

Here it seems like you would be doing something morally wrong by systematically taking the pills between $t_{0}$ to $t_{10}$. A single pill alone will not lower the chances of fulfilling your moral obligation at $t_{10}$, but systematically consuming them will. Doing this, when you have good reason to believe it will drastically lower your chances of fulfilling your moral obligation (relative to, say, not taking the pills), seems morally wrong - even if, in principle, this moral wrongness could be outweighed. ${ }^{9}$

Two important qualifications to (D) and (D*). First, consider:

Murder: You spend most evenings at home with your partner. You realise that if you killed your partner and got away with it you would have much more free time in the evenings to volunteer at your local food bank. Despite this, you decide not to kill your partner.

Obviously, you have done the morally right thing in Murder. But notice that by choosing not to kill your partner, you have done something that you know - relative to killing them - drastically lowers the chances of your fulfilling your moral obligations to aid the extremely poor.

One may think that since, e.g., (D) claims that performing actions that you have good reason to believe will drastically lower your chances of fulfilling a moral obligation is pro tanto morally wrong, then this entails you have done something pro tanto morally wrong by not killing your partner and, in turn, that you in fact have a pro tanto moral obligation to kill your partner in Murder.

This is implausible. You do not do anything even pro tanto morally wrong by not killing your partner in Murder. Prima facie, no view about the moral status of chance-affecting actions should entail that you do something pro tanto morally wrong in not performing an action that is itself morally impermissible. Equivalently, it should not entail that you are under a pro tanto moral obligation to perform some action the performance of which is independently morally wrong - such as killing your partner in Murder.

So, if (D) entails you have done something pro tanto morally wrong by not killing your partner, then (D) is false. The same is true, of course, of (D*) in analogous systematic act cases.

(D) and $\left(D^{*}\right)$ can, however, be easily qualified to avoid this consequence, whilst retaining all of their aforementioned attractive features, in this way: that the actions you are choosing from are themselves otherwise morally permissible actions. That is, they must be actions that, outside of this chance-affecting context, would be permissible to perform. ${ }^{10}$

(D), then, only concerns the moral status of chance-lowering actions that would be morally permissible to perform outside of the chance-affecting context in question. This ensures that (D) does not entail that you have done something pro tanto morally wrong by not killing your

\footnotetext{
${ }_{9}$ There is some imprecision regarding what number of tokens of an act-type count as systematic engagement in that act-type. There are, however, clear cases I take as paradigmatic examples: whilst a single cigarette does not count as systematic engagement in the act-type of smoking, it is clear that one can be systematically engaging in the act-type of smoking and where, by doing so, it becomes extremely likely that one will become physically unwell.

${ }^{10}$ In this sense, an action can be both otherwise morally permissible but be such that performing it in a given chance-affecting context is pro tanto morally wrong.
} 
partner in Murder. For killing your partner here is already not a morally permissible action, and, as such, is not a candidate for a chance-affecting action that may be pro tanto morally wrong to perform on this view. ${ }^{11}$

Second, take:

Job: You have been offered a high-paying job. The job, however, will put you at very high risk of physical harm. You have a choice between accepting this job or remaining unemployed. You choose to remain unemployed.

Declining the job is an action that you have good reason to believe will drastically lower your chances of fulfilling an obligation to assist those in extreme poverty, relative to taking the job, since you will forgo money to utilise in providing such aid. But you do not seem to have done anything wrong in remaining unemployed. If (D) entails that you have, then it looks false.

The reason, however, that you have not done something pro tanto morally wrong by making this chance-lowering choice seems to be that accepting the job would involve your incurring a heavy burden: putting your personal well-being at significant risk (so as to be able to donate to charity). You seem to be able to permissibly choose to avoid incurring this risk. This suggests that chance-affecting actions that you have good reason to believe will drastically lower your chances of fulfilling a moral obligation are not pro tanto morally wrong to perform when they are heavily burdensome on you.

So, the final qualification to (D) and (D*) is this: they concern only those actions that are not heavily burdensome on an agent to perform. ${ }^{12}$ With this qualification, (D) avoids the implausible entailment that you do something wrong in Job by choosing to remain unemployed. In doing so, it respects the fact that agents have at least some personal prerogative to live as they choose and are not morally obligated to perform actions that require them to unreasonably incur a heavy burden. ${ }^{13}$

So qualified, we have good reason to believe (D) and (D*) as they capture our intuitions in all of the cases discussed and avoid all of the problems identified with (A)-(C). I now defend these principles against three objections.

\footnotetext{
$\overline{{ }^{11}}$ This qualification of (D) entails that you have no pro tanto moral obligation at all to kill your partner in Murder, not that you do but that it is outweighed. But perhaps there are variants of Murder where we think you do have such an obligation but that it is outweighed by the wrongness of killing one's partner: for example, if the obligation you are drastically lowering the chances of fulfilling by not killing your partner is sufficiently stronger than one to volunteer for charity, such as one to save 1000 lives. Even if so (and we might reasonably doubt that), this is no objection to (D). (D) only concerns otherwise morally permissible actions. For that reason, it is consistent with (D) that we can in principle be under a pro tanto moral obligation to perform an otherwise morally impermissible action that is subsequently outweighed. But such a case does raise important questions regarding the precise relationship between the strength of the obligation one is affecting the chances of fulfilling and the moral status of actions that lower one's chances of obligation-fulfilment that I cannot pursue further here (but hope to elsewhere). I am very grateful to an anonymous reviewer for raising Murder-type cases and prompting me to clarify my view.

${ }^{12}$ I am using 'burdensome' here to refer to various forms of costliness to an agent. My claim here can be rephrased in other currencies of costliness (see Woollard 2016 for excellent discussion of these).

${ }^{13}$ There is, of course, some imprecision about exactly how burdensome an action must be for an agent's personal prerogative to disqualify such an act from meeting (D) or (D*). And, more generally, just how much an agent's personal prerogative allows them to knowingly perform drastically chance-lowering actions. There are, however, clear cases of heavily burdensome actions such as that in $J o b$ and it is such cases my principle concerns. I lack the space to exhaustively address the second question here. But it is an important question further work must address and that I hope to pursue elsewhere. I am very grateful to an anonymous reviewer for raising $J o b$ and prompting me to clarify my view.
} 
The first: since, on my view, any action that affects the objective probability of performing a moral obligation at a future time is a chance-affecting action, in principle any action can be chance-affecting. If so, then both (D) and $\left(\mathrm{D}^{*}\right)$ might be overdemanding: they potentially concern any action that an agent can perform, since it could be a chanceaffecting action.

This objection misunderstands (D) and (D*). (D) is a claim only about the pro tanto moral wrongness of a specific class of chance-affecting actions: otherwise permissible and not heavily burdensome actions that we have good reason to believe will drastically decrease the objective probability of fulfilling a given moral obligation at some future time.

By contrast, (A) is very demanding. It says that any action that lowers your chances of fulfilling a moral obligation is wrong. This entails that any chance-affecting action that lowers the chance of fulfilling a moral obligation even by a very small extent relative to another action is wrong. (D) and (D*) do not, concerning only certain actions agents have good reason to believe will (relative to at least one other action available) drastically lower the chance of their fulfilling a moral obligation.

A second objection: suppose we agree that in, e.g., Car* you would be doing something morally wrong by taking your car. This intuition, however, might be explained by your failing to meet some other moral obligation that you would be under that makes no reference to the fact that the action you perform somehow lowers your chance of fulfilling a moral obligation. For example, in $\mathrm{Car}^{*}$ and Pill you might be under a general moral obligation captured by:

(Transmission): If $\mathrm{X}$ ought to $\Phi$, all things considered, and $\Psi$ is a necessary means to $\Phi$ ing, then $X$ should also $\Psi$, all things considered (Cordelli 2018: 383 ). ${ }^{14}$

According to (Transmission), if I ought to help my friend (all things considered), and if my going to their house is a necessary means for me to help my friend, then I also ought to go to my friend's house (all things considered).

Perhaps, then, in $\mathrm{Car}^{*}$ the moral wrongness of taking my car is explained not by reference to (D) and the chance-lowering feature of that action, but, rather, that taking the bus is a necessary means to being able to help Adam. And since I ought to help him, and I failed to do something that is necessary to do that, then I have done something wrong by taking the car.

Even if (Transmission) is true, however, it cannot explain the moral wrongness of taking my car in $\mathrm{Car}^{*}$. For whilst taking my car will lower the chances of fulfilling my moral obligation to Adam, it is not a necessary means to help him. Rather, it will only lower my chances of being able to do so. This chance-lowering does not render taking the bus a necessary means to help Adam, but only the one that is more likely - relative to the car - to ensure that I can fulfil my obligation. So, this objection fails.

One might respond by suggesting that a revised form of (Transmission) can explain the wrongness of the chance-lowering actions that (D) and (D*) concern:

(Transmission*): If $\mathrm{X}$ ought to $\Phi$, all things considered, and $\Psi$ is a reasonable step to ensure that $X$ will $\Phi$, then $\mathrm{X}$ should also $\Psi$, all things considered.

In Car* and Pill, e.g., you might be under a general moral obligation to take all reasonable steps to ensure that you fulfil a moral obligation. By taking your car, or systematically consuming the pill, you would violate that obligation since they are actions that the agent

${ }^{14}$ See Setiya 2007: 649-73, 660 and Broome 2013: 126 for discussion. 
has good reason to believe will drastically lower their chances of fulfilling their moral obligation. The failure to meet (Transmission*), then, might be the best explanation of our intuitions in these cases - and not (D) or (D*).

It is unclear whether (Transmission*) is true. But even if it is, there will be some explanation for why it is. Absent one, positing the existence of this general obligation alone as the best explanation for the intuition that certain chance-affecting actions are pro tanto morally wrong leaves unexplained why we may have this additional moral obligation.

But (D) and (D*) provide the desired explanation. For if it is pro tanto morally wrong to perform an action (or engage in a type of action) that we have good reason to believe will drastically decrease the chance of fulfilling a moral obligation in the future, then - on standard accounts of the relationship between moral wrongs and obligations - (D) and (D*) entail that we have a pro tanto moral obligation not to perform such actions.

The existence of this moral obligation would explain why there is a general obligation to take reasonable steps to ensure that we fulfil our moral obligations: because it is wrong to do those things that, absent weightier competing moral considerations, will drastically decrease our chances of fulfilling a moral obligation in the future. So, this revised form of the second objection fails.

Finally, one might protest that modal changes in a case can change what moral obligations an agent is under, and that this can explain why we find actions like those in Car* morally wrong. For example, perhaps once you enter your car and start driving you generate an additional moral obligation to change your behaviour and rectify having rendered the chance of your making it to Adam drastically lower than some other action you could perform (e.g. taking the bus).

But, again, the presence of a moral obligation to rectify your behaviour in $\mathrm{Car}^{*}$ calls for explanation. And (D) provides this: the reason that you are (suppose) under a (pro tanto) moral obligation to get out of your car and catch the bus is because driving your car to Adam's is, relative to taking the bus, an action you have good reason to believe will make it very unlikely you will fulfil your obligation to Adam. This concern, then, provides no reason to reject (D) (or (D*) in analogous cases) in light of modal changes in cases such as Car* (or Pill).

\section{Conclusion}

In $\S 1, I$ introduced the question of the moral status of chance-affecting actions, the specific question of whether actions that lower the chances of fulfilling a moral obligation are ever morally wrong, and motivated concern with their answers. I argued in $\$ 2$ that this is the most plausible answer considered: an agent performing an otherwise permissible and not heavily burdensome action (or systematically engaging in a type of such action) that they have good reason to believe will drastically lower the chances of fulfilling a moral obligation, relative to at least one alternative action available, is pro tanto morally wrong.

I make three sets of concluding remarks. First, if (D) or (D*) is true, then this is a significant finding for normative and practical ethical inquiry. Prima facie, (D) entails that actions we regularly perform that lower the chances of fulfilling a moral obligation in the relevant way are pro tanto morally wrong. And (D*) appears to entail that many types of actions the systematic performance of which would meet it - such as, inter alia, smoking, regular drug abuse, and severe neglect of one's physical and mental well-being - are pro tanto morally wrong. This provides grounds to generate novel arguments regarding the moral status of such actions. 
The plausibility of (D) and (D*) also makes answering a certain recalcitrant question more urgent. (D) concerns choices between at least two chance-affecting actions, and (D*) concerns choices to systematically perform a type of action. But there may be mixed cases where one can perform an action that will lower one's chances of fulfilling a moral obligation, but where that action is member of a set in which other members would either return one's chance of performing some obligation to pre-first-action levels or even increase one's chance of fulfilling that obligation. What to say of such cases depends, in part, on the vexed question of how we should individuate actions when asking of their moral status.

Second, if (D) and $\left(D^{*}\right)$ are true, this generates a new adequacy condition on general normative ethical theories. Any such theory must explain the seeming pro tanto moral wrongness of the class of chance-affecting actions these principles concern - and the corresponding pro tanto moral obligation not to perform these actions.

Deontological theories that recognise pro tanto moral claims may appear best placed to do so. A consequentialist, however, might attempt to capture our intuitions here without admitting of pro tanto moral claims by taking the likelihood of promoting future good as part of the consequence of an action. And a virtue ethicist may alternatively suggest appropriate forward thinking as a virtue that accommodates the intuitions discussed above. ${ }^{15}$

There is a dispute to be had here. But ultimately such theories, unless they can show (D) or (D*) false, must explain their plausibility. If they cannot, then not only do they leave the moral status of such actions unexplained, but, if some other theory can, then this provides the grounds for novel arguments against theories that fail to do so.

Third, there is much more to be said in answer to (The Question), and the more general question of the moral status of chance-affecting actions. This paper has aimed to motivate, and make a first attempt at, answering these questions. If successful, it will inevitably raise more questions than it answers. Note, for example, one of the simplifying assumptions I made in $\S 1$ : bracketing whether the moral obligation one affects the chances of fulfilling is met and assuming the moral status of chance-affecting actions does not depend upon whether said obligation is met.

We might ask whether, in general, the moral status of actions that lower or increase one's chance of fulfilling a moral obligation always are independent of whether the obligation concerned is met. Questions also remain regarding the cases I labelled mixed above, what the relationship between the strength of an obligation and the moral status of chance-affecting actions regarding it is, and to what extent costliness to an agent may relieve one of being under any pro tanto moral obligation to (not) perform certain chanceaffecting actions.

But we might also ask: whether we have a moral obligation to increase (or maximise) the chance of fulfilling our moral obligations, whether the truth of principles like (D) or (D*) can provide a defence of other normative ethical claims (e.g. of the moral wrongness of imposing risk by appeal to lowering one's chances of fulfilling an obligation not to harm or allow harm), whether the fact that an obligation you are affecting the chances of fulfilling is generated by a specific kind of duty affects the moral status of a chance-affecting action (such as directed or undirected, or perfect or imperfect ones), and whether or not there is any difference in the moral status of chance-affecting actions when they concern obligations we have to those we stand in special relations to.

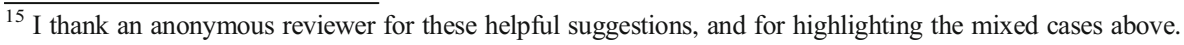


These are questions for another time, and questions that a complete account of the moral status of chance-affecting actions must answer. But I hope here to have increased our chances of successfully determining the moral status of (at least some) chance-affecting actions. ${ }^{16}$

Open Access This article is licensed under a Creative Commons Attribution 4.0 International License, which permits use, sharing, adaptation, distribution and reproduction in any medium or format, as long as you give appropriate credit to the original author(s) and the source, provide a link to the Creative Commons licence, and indicate if changes were made. The images or other third party material in this article are included in the article's Creative Commons licence, unless indicated otherwise in a credit line to the material. If material is not included in the article's Creative Commons licence and your intended use is not permitted by statutory regulation or exceeds the permitted use, you will need to obtain permission directly from the copyright holder. To view a copy of this licence, visit http://creativecommons.org/licenses/by/4.0/.

\section{References}

Broome J (2013) Rationality through reasoning. Oxford University Press, Oxford

Cordelli C (2018) Prospective duties and the demands of beneficence. Ethics 128(2):373-401

Elson L (2019) Probabilistic promotion and ability. Ergo 6(34):967-998

Goodin RE (2012) Excused by the unwillingness of others? Analysis 72(1):18-24

Herzog L (2018) Reclaiming the system: moral responsibility, divided labour, and the role of organizations in society. Oxford University Press, Oxford

Hoefer C (2005) The third way on objective probability: a sceptic's guide to objective chance. Mind 116(463): 549-596

Lewis D (1980) A subjectivist's guide to objective chance. In: Harper WL, Stalnaker R, Pearce G (eds) Ifs. Reidal, Dordrecht, pp 267-297

Nina E (2017) A naturalist's guide to objective chance. Philos Sci 84(3):480-499

Nussbaum M (2004) Beyond 'compassion and humanity': justice for nonhuman animals. In: Nussbaum M, Sunstein C (eds) Animal rights: current debates and new directions. Oxford University Press, New York, pp $299-320$

Setiya K (2007) Cognitivism about instrumental reason. Ethics 117(4):649-673

Woollard F (2016) V-dimensions of demandingness. Proc Aristot Soc 116(1):89-106

Publisher's Note Springer Nature remains neutral with regard to jurisdictional claims in published maps and institutional affiliations.

\footnotetext{
${ }^{16}$ I have discussed the ideas in this paper with many people, all of whom I am very grateful to. In particular, I am extremely grateful to my doctoral supervisors Roger Crisp and Tim Williamson, and to Matthew Collier, Nathaniel Helms, Geoff Keeling, Tien-Chun Lo, Lucy Mellor, Martin Pickup, Theron Pummer, Gonzalo Rodriguez-Pereyra, and Abigail Saks, for both exceptionally helpful written feedback on, and many conversations over, versions of this paper. I am also extremely grateful to several anonymous reviewers for their very helpful comments that greatly improved the paper. I am similarly grateful to attendees of a presentation of this paper at the Oriel Philosophy Seminar for their generous feedback and discussion. Finally, I also thank audiences at Oriel Talks, St. Edward's School, Oxford, and Magdalen College School, Oxford for their stimulating questions and discussion. This work was supported by an Arts and Humanities Research Council (AHRC) Studentship from the Oxford AHRC Doctoral Training Partnership.
} 